\title{
EFFECTS OF STIMULATION OF PONTINE AND BULBAR RETICULAR FORMATION UPON SPINAL MOTONEURONS OF THE CAT
}

\author{
Kazuo SASAKI, Tsutomu TANAKA and Kazuo MoRI* \\ Department of Physiology, Faculty of Medicine, \\ Kyoto University, Kyoto
}

Numerous studies have been reported on facilitatory and inhibitory influences of reticular formation ( $R F$ ) in the lower brain stem upon motor performances. In initial studies effects elicitable from the reticular structure were found to be of generalized and non-reciprocal nature ${ }^{9,13,17,19)}$ and accordingly the RF was divided into facilitatory and inhibitory areas. An account for the decerebrate rigidity was also given from this viewpoint. However, in subsequent studies carried out under more physiological conditions, reciprocal nature of reticular influences upon antagonistic muscles has been emphasized ${ }^{3,20)}$, and the explanation of the decerebrate rigidity based on earier findings was also challenged $^{20)}$. Discrepancies of these results seem to be due to different experimental conditions, and unified solution of these problems requires further detailed studies.

In almost all studies mentioned above, experiments were carried out using repetitive stimulation of $\mathrm{RF}$ as conditioning, since attention was mainly focused on the reticular influence upon posture. On the other hand, there are several papers which have intended to analyse the mechanisms of reticular facilitation and inhibition, using single pulse stimulation of $\mathrm{RF}$ and recording unitary activities of spinal neurons ${ }^{7,21)}$. One of our previous works ${ }^{15)}$ was also carried out in the same intention. The present study is likewise an analytical approach to the suprasegmental control over the spinal function.

\section{METHODS}

Most of the methods used in this study were similar to those described in the preceding paper ${ }^{15}$ ). Craniotomy and laminectomy of lumbosacral segments were performed under Nembutal $(25 \mathrm{mg} / \mathrm{kg}$, intraperitoneal) or ether anesthesia. In some cases the tentorium cerebelli was removed to facilitate insertion of stimulating electrodes into pontine and bulbar regions. Bilateral peroneal and tibial nerves were exposed and placed on bipolar silver wire electrodes, with peripheral nerve ends

Received for publication August 4, 1961.

* 佐々木和夫, 田中 任, 森 和夫 
sectioned.

The head of the animal was clamped in a stereotaxic intrument and the lumbosacral part was rigidly fixed in a frame specially designed for convenient micromanipulation of recording electrode and for assured fixation of the spinal cord under very light anesthesia. The animal was then left untouched for five to six hours without any additional administration of anesthetics. Intravenous injection of dtubocurarine and artificial ventilation were available only when muscular movements unavoidable in the case of repetitive stimulation of the lower brain stem interfered with continuous intracellular recording.

Stimulating electrodes for the brain stem were of steel wire with diameter of about $0.3 \mathrm{~mm}$ and coated except at the tip. Five to seven pairs of those electrodes were bundled up in advance and fixed to a manipulator with a relative position of the tips so arranged that, when they were inserted en bloc into the brain stem to a certain depth, the tips of each pair should have been located in the focus to be stimulated. The electrodes were introduced through cerebellum, but the cerebellum was considered to be in physiological condition, because the fastigial nucleus stimulated on occasion showed normal influence upon spinal activity. Single rectangular current pulse of 2-3 msec. duration or a short train lasting 2-3 msec. of rectangular pulses (pulse width, $0.05-0.10 \mathrm{msec}$; frequency, 5,000-10,000/sec; voltage, 1-5V) was given to each focus.

Bilateral L6 and L7 ventral roots, sometimes also L5 and S1, were severed and L6
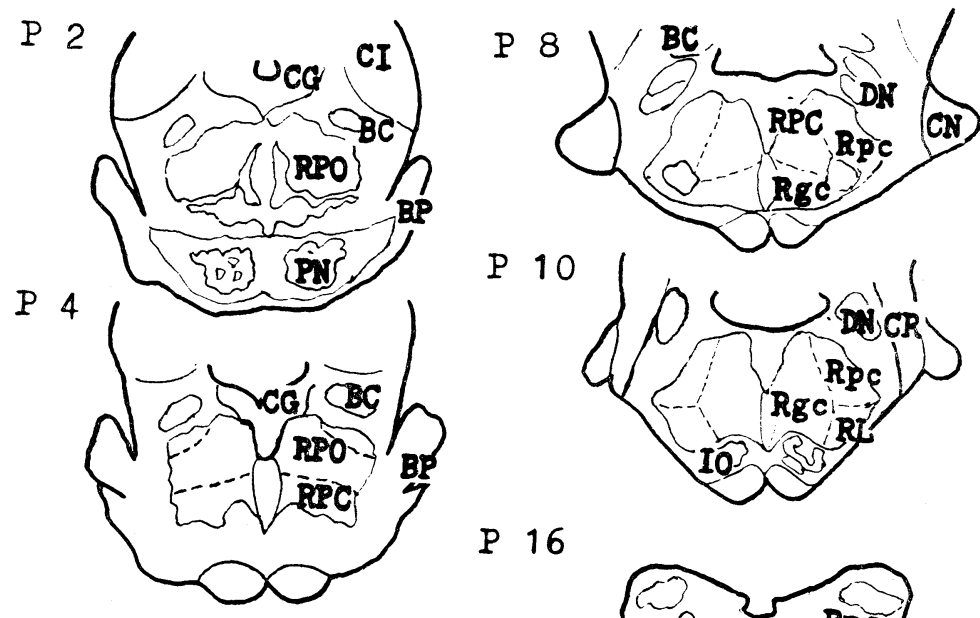

P 16

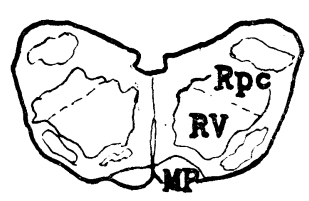

FIG. 1. Maps of transection of the cat's brain stem modified from TORVIK and BRODAL ${ }^{22)}$, showing transverse planes of posterior 2, 4, 8, 10 and $16 \mathrm{~mm}$ of HoRSLEY-ClaRKe stereotaxic instrument.

$\mathrm{BC}$ : brachium conjunctivum. $\mathrm{BP}$ : brachium pontis. $\mathrm{CG}$ : central grey matter. $\mathrm{CI}$ : colliculus inferior. $\mathrm{CN}$ : cocholear nuclei. $\mathrm{CR}$ : corpus restiforme. DN : Deiters' nucleus. IO : inferior olive. MP : medullary pyramid. Rgc: nucleus reticularis gigantocellularis. Rpc: nucleus reticularis parvocellularis. RPC: nucleus reticularis pontis caudalis. RPO: nucleus reticularis pontis oralis. $\mathrm{RV}:$ nucleus reticularis ventralis. 
and L7 ventral roots of the same side were put together and placed on a pair of silver electrodes for recording and stimulation. An RC coupled amplifier feeding a cathode-ray oscilloscope was used for recording from peripheral nerves.

For recording intracellular potentials from spinal neurons, glass micropipettes, whose resistance was $10-20 \mathrm{M} \Omega$ when filled with $3 \mathrm{M}-\mathrm{KC} 1$ or $2 \mathrm{M}$-potassium citrate, and a DC amplifier with a neutralized capacity input were employed.

Histological investigation At the end of the experiment, anodal currents were passed through the stimulating electrodes in the brain stem and iron deposits in the brain tissue were stained with the method of Tirmann-Schmelzer. The location of the electrode tips was thus examined by making serial sections in each case. The available stereotaxic atlas of the lower brain stem was rather imperfect, so that the histological investigation was always necessary.

Fig. 1 shows maps of transection of the cat's brain stem modified from ToRvik and BRODAL ${ }^{22}$. The location of the stimulating electrodes was checked in reference to their maps.

\section{RESULTS}

1. Influences of the lower brain stem stimulation upon the spinal monosynaptic reflex.

The effects of single stimulation of the lower brain stem on the size of spinal monosynaptic reflex were studied by recording discharges from the ventral roots. Test stimuli delivered to the peroneal or tibial nerve of either side were of intensity submaximal to group Ia fibers in respective nerves. These were delivered repeatedly in combination with the conditioning brain stem stimulation at time intervals increasing successively from 0 to $60 \mathrm{msec}$. FIG. 2 shows the time course of facilitatory and inhibitory influences from the stimulated foci upon the amplitude of monosynaptic reflex discharges.

Midbrain RF The effect of stimulation of midbrain $\mathrm{RF}$ has already been reported $^{15)}$. For comparison the result is presented in FIG. 2A; facilitation of the flexor reflex and facilitation, followed by inhibition, of the extensor reflex on both bodily sides.

Pontine RF Examples of stimulation of pontine RF are presented in FIG. $2 \mathrm{~B}$ and $\mathrm{C}$, the former illustrating results obtained by stimulating its rostrolateral part and the latter ones from its rostro-medial part (RPO in FIG. 1). A conspicuous feature was a vigorous inhibition of the monosynaptic reflex set up by tibial nerve afferents, though a slight facilitation preceded the inhibition in some cases. The inhibitory effect was at times dominant to the ipsilateral side (FIG. 2B), but usually undistinguishable between both sides (FIG. 2C). A slight facilitation was noted upon the reflex elicited by peroneal nerve stimulation. When compared with the effects obtainable from the midbrain RF, the pontine RF, especially its rostral part, exerted stronger inhibition to the extensor reflex and weaker facilitation to the flexor reflex, the effects resembling those obtainable by stimulating the red nucleus. 

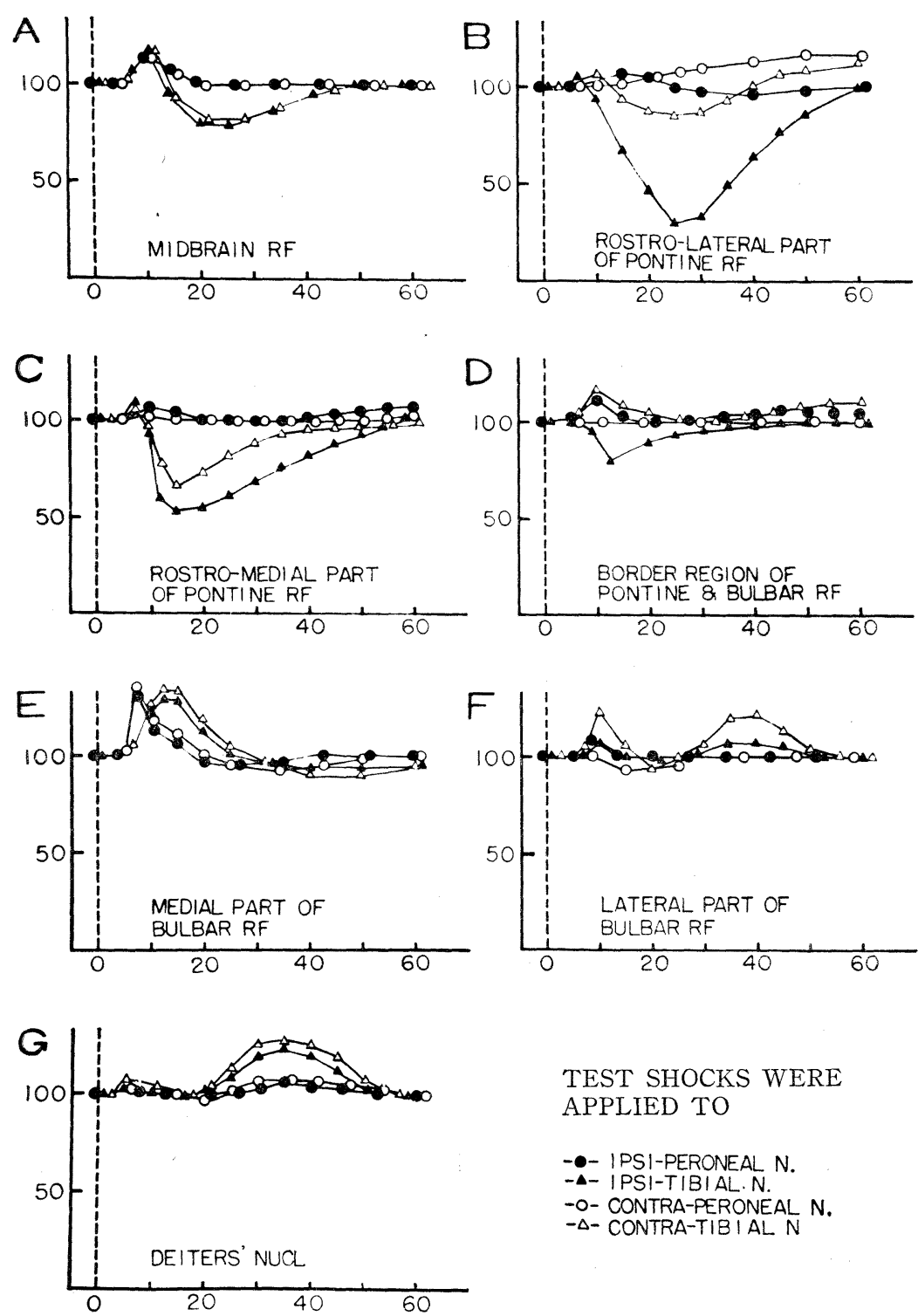

TEST SHOCKS WERE APPLIED TO

$-\bullet-\mid P S I-P E R O N E A L$
$-\triangle-$

-O- CONTRA-PERONEAL N.

$-\triangle-$ CONTRA-TIBIAL $N$

FIG. 2. The time course of influences of stimulating brain stem foci upon the height of extensor and flexor monosynaptic reflexes.

Ordinates: reflex amplitudes recorded from the ventral roots in percentages of the control reflex size.

Abscissae: time intervals in millisecond between conditioning and test stimuli. 
When the stimulating electrodes were in a more caudal part of pontine RF, the effect became manifold and akin to that of stimulation of bulbar RF.

Bulbar $R F$ Influences of stimulation of bulbar $\mathrm{RF}$ were rather intricate and various combinations of facilitation and inhibition came to appear on bilateral flexor and extensor motoneurons. Representative examples are illustrated in FIG. 2D, E and F.

In the case of $\mathrm{D}$, a result frequently encountered when the border region between pons and medulla oblongata was stimulated, the reflexes set up from contralateral tibial and ipsilateral peroneal nerve were facilitated, while that of ipsilateral tibial nerve was inhibited. With the electrode tips located a little more caudal, there were a good number of foci from which the reflex set up from the tibial nerve could markedly be facilitated $(E$ and $F)$. The facilitatory influences shown in E, obtained on stimulation of medial bulbar RF ( $\mathrm{Rgc}$ in FIG. 1), have rather simple time courses which are almost alike on the opposite sides. Diagram $\mathrm{F}$ is the effect of stimulation of lateral bulbar RF and shows two facilitatory surges, which are especially distinct upon the reflex elicited by contralateral tibial stimulation (open triangles). Facilitation of similar time course resulted also from single stimulus to Deiters' nucleus as is presented in G.

Deiters' nucleus Stimulation of the Deiters' nucleus produced a facilitatory effect, usually bilaterally, upon the reflex set up by tibial nerve volleys. On occasion, similar effect, though much weaker, was found also on the reflex from the peroneal nerve. The time course of the facilitation consisted in general of two components, the one starting at a latency of several msec. but sometimes only to grow to an extent scarcely noticeable, while the other starting at a latency of $15-20 \mathrm{msec}$. and lasting for an interval of over $30 \mathrm{msec}$. As seen in $G$, it is characteristic of the latter that the facilitatory influence grows as slowly as it decays.

2. Postsynaptic potentials in spinal alpha motoneurons elicited by stimulation of lower brain stem.

After testing influences of the brain stem stimulation upon the monosynaptic reflex, microelectrodes were inserted into lower lumbar segments of the spinal cord and the intracellular potentials of alpha motoneurons were recorded. Upon stimulation of the brain stem, various changes of the intracellular potential could be induced, which seemed generally speaking fairly characteristic of each focus stimulated.

Pontine RF (Rows A, B and C in Fig. 3) Stimulation of the rostro-medial part of pontine RF set up bilaterally IPSP's in extensor motoneurons at latencies of $12-15 \mathrm{msec}$. The IPSP's were usually preceded by a slight depolarization, which sometimes could induce an action potential (Row A, IE and CE). The same stimulation evoked EPSP's in flexor motoneurons at latencies of 5$10 \mathrm{msec}$. which were usually subliminal for motoneuron discharge and some- 


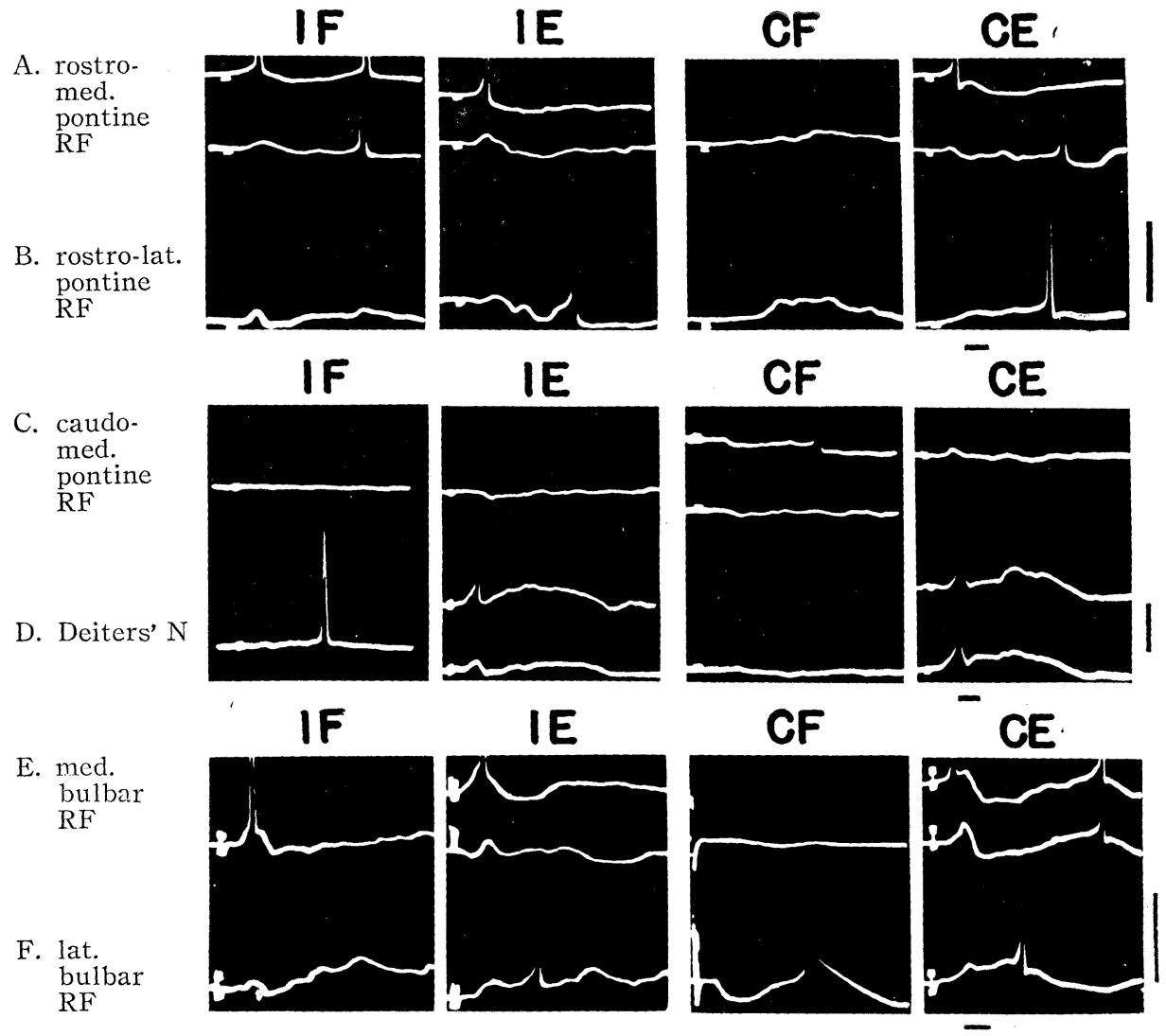

FIG. 3. Effects of the brain stem stimulation upon the intracellular potential of lumbar alpha motoneurons. Stimulated sites are indicated to the left margin of each row. Records were obtained from twelve motoneurons in three different cats, each four records from the same animal being juxtaposed from left to right (IF : ipsilateral flexor; IE : ipsilateral extensor; $\mathrm{CF}$ : contralateral flexor; $\mathrm{CE}$ : contralateral extensor motoneurons). One and the same position of stimulating electrodes for traces in each row. Stimulus artefact near the left end of each trace.

Time marks : $10 \mathrm{msec}$ Voltage calibrations : $25 \mathrm{mV}$

times even failed to appear in contralateral flexors (Row A, IF and CF). Results in the same motoneurons as in row A of stimulation of rostro-lateral part of pontine RF near brachium conjunctivum are illustrated in row B. EPSP's are set up in the ipsilateral flexor motoneurons at latencies of about $10 \mathrm{msec}$. and IPSP's in the ipsilateral extensor motoneurons at latencies of nearly 20 msec. In the contralateral flexor and extensor motoneurons the same stimulation elicits depolarizing PSP's of longer duration at longer latencies.

Examples of stimulation of a more caudal part of pontine RF are presented 
in row C. It produces IPSP in the ipsilateral extensor motoneuron at a latency of about $15 \mathrm{msec}$. and EPSP in the contralateral extensor at a latency of about $10 \mathrm{msec}$. In the contralateral flexor motoneuron, it produces IPSP at a latency of about 15 msec.

Deiters' nucleus (Row D) With the stimulating electrodes inserted within or near Deiters' nucleus, depolarizing PSP's were set up bilaterally in extensor motoneurons. The PSP's usually appeared as two separate groups, an early group and a late one. The early group was set up at a latency of about 10 msec., lasting for a relatively short time, but was so potent that the motoneuron often fired from it. The late group, on the other hand, showed a latent time of $15-20 \mathrm{msec}$. or more and had a long duration with gradual rise and fall (Row D, IE and $\mathrm{CE}$ ). The gradual depolarization due to this late group was seldom capable of firing motoneurons, although the depolarization often surpassed the firing level of the early EPSP's. Stimulation of Deiters' nucleus showed only insignificant effects upon bilateral flexor motoneurons.

Bulbar RF (Rows $\mathrm{E}$ and $\mathrm{F}$ ) The effects of stimulation of bulbar RF were invariably complicated with respect to all areas stimulated. Some resembled the effect of pontine RF stimulation, while others that elicitable from the midbrain. However, a special feature commonly found in most cases of stimulating certain loci in the bulbar RF was, contrary to stimulation of other parts of $\mathrm{RF}$, that marked EPSP's were produced in extensor motoneurons. Examples are presented in rows $\mathrm{E}$ and $\mathrm{F}$ where stimuli have been applied to the medial (E) and lateral $(\mathrm{F})$ parts of bulbar $\mathrm{RF}$ ( $\mathrm{Rgc}$ and $\mathrm{Rpc}$ in FIG. 1). In row E, EPSP's are noted at latencies of 5-10 msec. in all motoneurons except for contralateral flexor and, in addition to this, EPSP's with slow time course appear in the contralateral extensor motoneuron at a longer latency. Effects resulted from the lateral part (Row F) seem complicated in these motoneurons. Generally speaking, the result was excitatory to the ipsilateral flexor, ipsilateral extensor and contralateral extensor motoneurons, and inhibitory to the contralateral flexor motoneuron.

In general, the EPSP's at the short latency revealed relatively brief and simple time course, while those appeared at a longer latent time had a prolonged duration with slow rise and decay. The latter was most conspicuous when the lateral part of bulbar RF or Deiters' nucleus was stimulated, and was apparently responsible for the late facilitation of the monosynaptic reflex described above (FIG. 2, F and G). It is of interest to note that the late group of EPSP's was conspicuous in some motoneurons while it was almost abolished in others. Its presence or absence seemed to be correlated with the duration of after-hyperpolarization following single spike discharge from the motoneuron under study. Full treatment of this problem will appear in a subsequent paper.

Firing level of motoneuron In FIG. 4 are illustrated various time courses of 
PSP's set up in two extensor motoneurons from different foci in the brain stem. In example I, stimuli have been applied to the ventral root (A), dorsal root (B), medial part of bulbar RF (C), caudal part of pontine RF (D), lateral part of bulbar RF (E) and near Deiters' nucleus $(F)$, respectively. The time course of PSP's in records $\mathrm{C} \sim \mathrm{F}$ is mostly in accordance with the description given above for respective foci. Now it can be seen from this figure that the
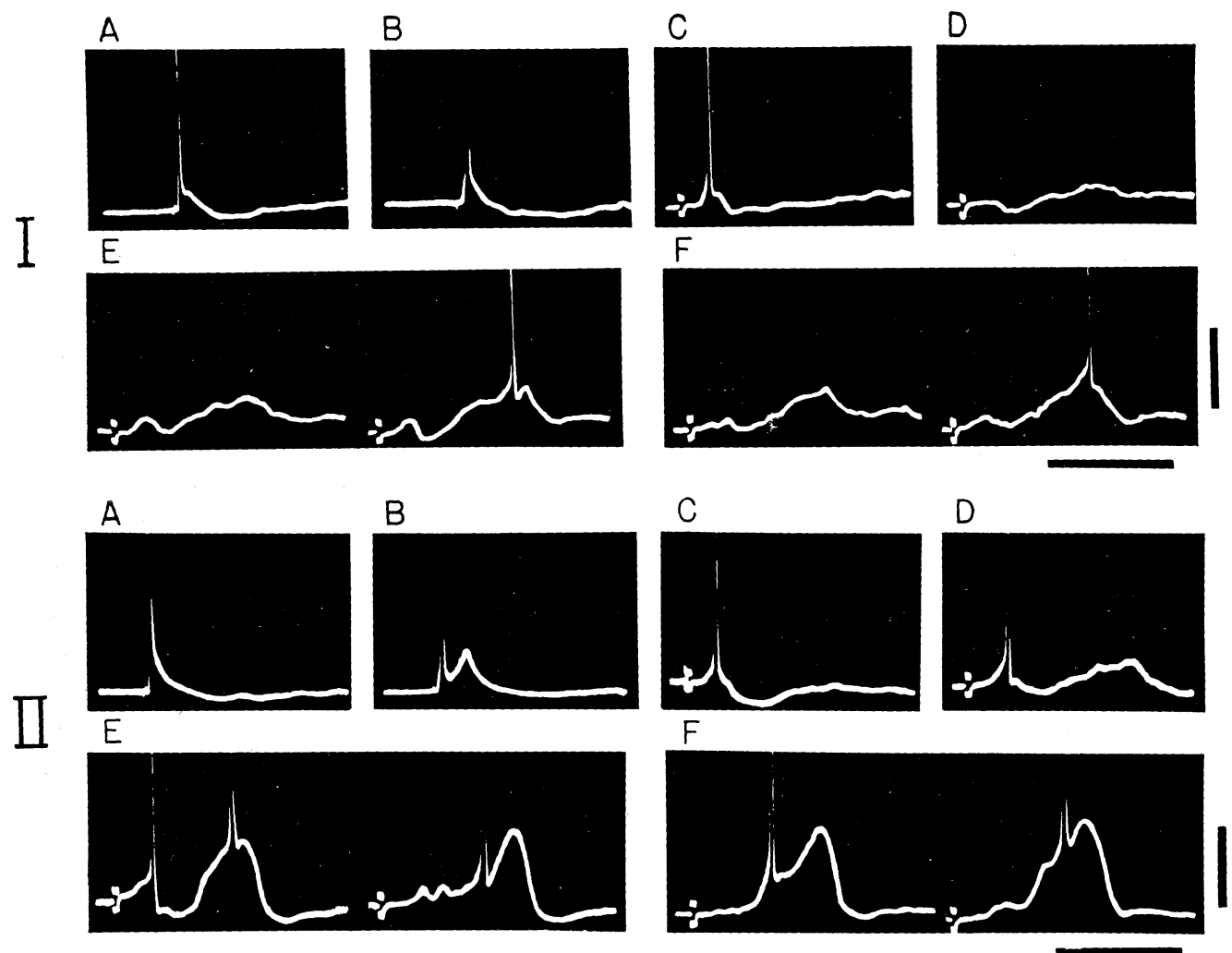

FIG. 4. Varying firing levels in the same spinal motoneurons. Responses of two motoneurons are presented.

I. Stimuli are applied to the ventral root (A), the dorsal root (B), the medial part of contralateral bulbar RF (C), the caudal part of contralateral pontine RF (D), the lateral part of contralateral bulbar RF (E) and near Deiters' nucleus of the contralateral side (F). In $E$ and $F$, the same stimulation sometimes fails to set up action potential. Note much higher firing levels in $\mathrm{E}$ and $\mathrm{F}$, as compared with $\mathrm{B}$ and $\mathrm{C}$.

II. Stimuli are applied to the ventral root (A), the dorsal root (B), the medial part of contralateral bulbar RF $(C)$, the lateral part of contralateral bulbar RF (D), the contralateral pontine RF near the brachium pontis (E) and the contralateral brachium pontis (F). Compare firing levels in $\mathrm{E}$ and $\mathrm{F}$ with those of $\mathrm{B}, \mathrm{C}$ and $\mathrm{D}$.

Time marks : $50 \mathrm{msec}$. Voltage calibrations : $25 \mathrm{mV}$. 
depolarization level of motoneuron membrane at which the motoneuron fires depends on the rate of change in the membrane potential due to PSP's. In B and C, EPSP's are set up by each stimulus with rather steep depolarization which fires the motoneuron at a level of about $7-10 \mathrm{mV}$. In records $\mathrm{E}$ and $\mathrm{F}$ PSP's are set up forming two successive elevations, the one appearing at latencies of about $7 \mathrm{msec}$. and the other at latencies of $20-30 \mathrm{msec}$. The latter PSP's show slowly increasing depolarization and fire the motoneuron only when it has reached fairly higher level of about $15 \mathrm{mV}$ in $\mathrm{E}$ and $20 \mathrm{mV}$ in $\mathrm{F}$.

Example II illustrates variable firing levels in one and the same motoneuron more markedly. Here, stimuli were applied to the ventral root (A), dorsal root $(B)$, medial part of bulbar $R F(C)$, lateral part of bulbar $R F(D)$, pontine $\mathrm{RF}$ near brachium pontis $(\mathrm{E})$ and brachium pontis $(\mathrm{F})$. The brachium pontis was not a primary target of this research but was hit by chance in a few cases of misguided electrode insertion, so that it might be adventurous to regard these records as typical results. It is obvious, however, that the depolarizing PSP's in E and F, which appear at a latency of 20-30 msec. with gradual increase and sudden fall, initiate the action potential at much higher level of depolarization than that resulted from other stimulations.

3. Effects of repetitive stimulation of the lower brain stem upon the motoneuron activity.

Repetitive stimulation of the pontine RF usually produced an effect interpretable as a summated effect of single stimulations of the same site. FIG. 5 shows such a summation of IPSP's and its effect on the firing rate of motoneurons. In A, the stimulation frequency was first gradually increased from 20 to 100 per second (upper record) and then decreased again to the initial frequency (lower record) by manual rotation of the dial. Single pulse stimulation elicited IPSP at a latency of about $10 \mathrm{msec}$. which was sometimes preceded by slight depolarization. At a stimulation rate of about 100 per second, nearly continuous hyperpolarization was produced, whose amplitude in this case slightly surpassed that of single IPSP. In the motoneurons firing spontaneously, such a hyperpolarization naturally decreased the rate of maintained firing, as is shown in B and C.

The effect of repetitive stimulation of bulbar RF was not necessarily equal to the sum of the effects of single stimulations, but frequently remarkable for its after-effect lasting for a considerable interval. FIG. 6 gives two examples of common results which were obtained from two extensor motoneurons by stimulating bulbar RF. Each upper row is the record of single stimulation repeatedly given at a frequency of about 8 per second and each lower row is that of repetitive stimulation at a frequency of 75 per second. In each motoneuron single pulse stimulation of about $3 \mathrm{msec}$. duration elicited EPSP at a short latency with occasional spike discharge from it. There was also a more or less distinct tendency of inducing a late group of EPSP's at longer latencies. 
Repetitive stimulation of the same site resulted in summation of EPSP's of short latency which induced repetitive discharge of motoneuron spikes. The firing rate was varying from cell to cell, depending on the stimulation too. In any case, the motoneurons showed adaptation, at least partially, to sustained summation of EPSP's, as revealed in decreasing firing rate. After stimulation was discontinued, the motoneurons showed anew a slow wave-like depolariza-

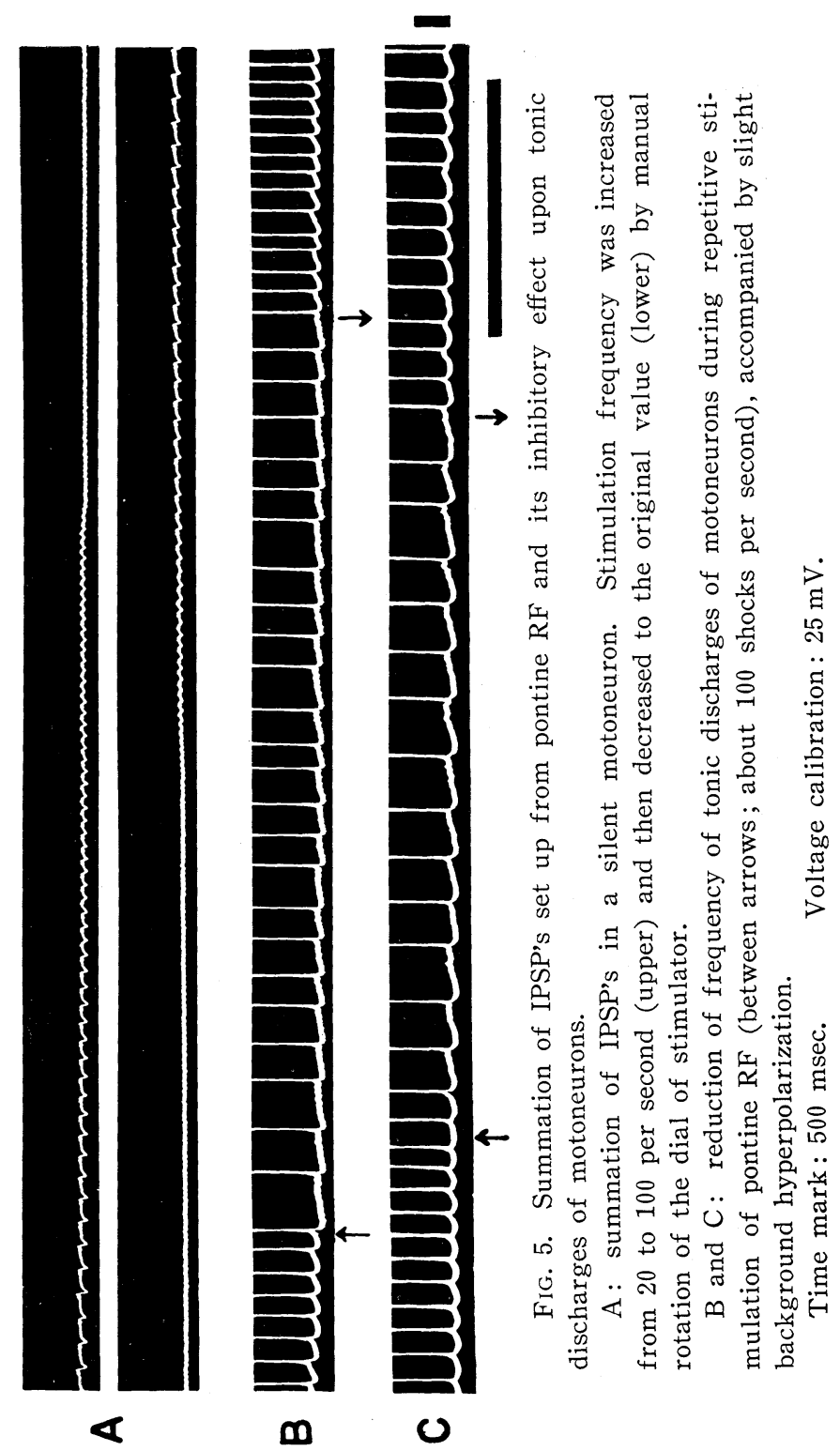




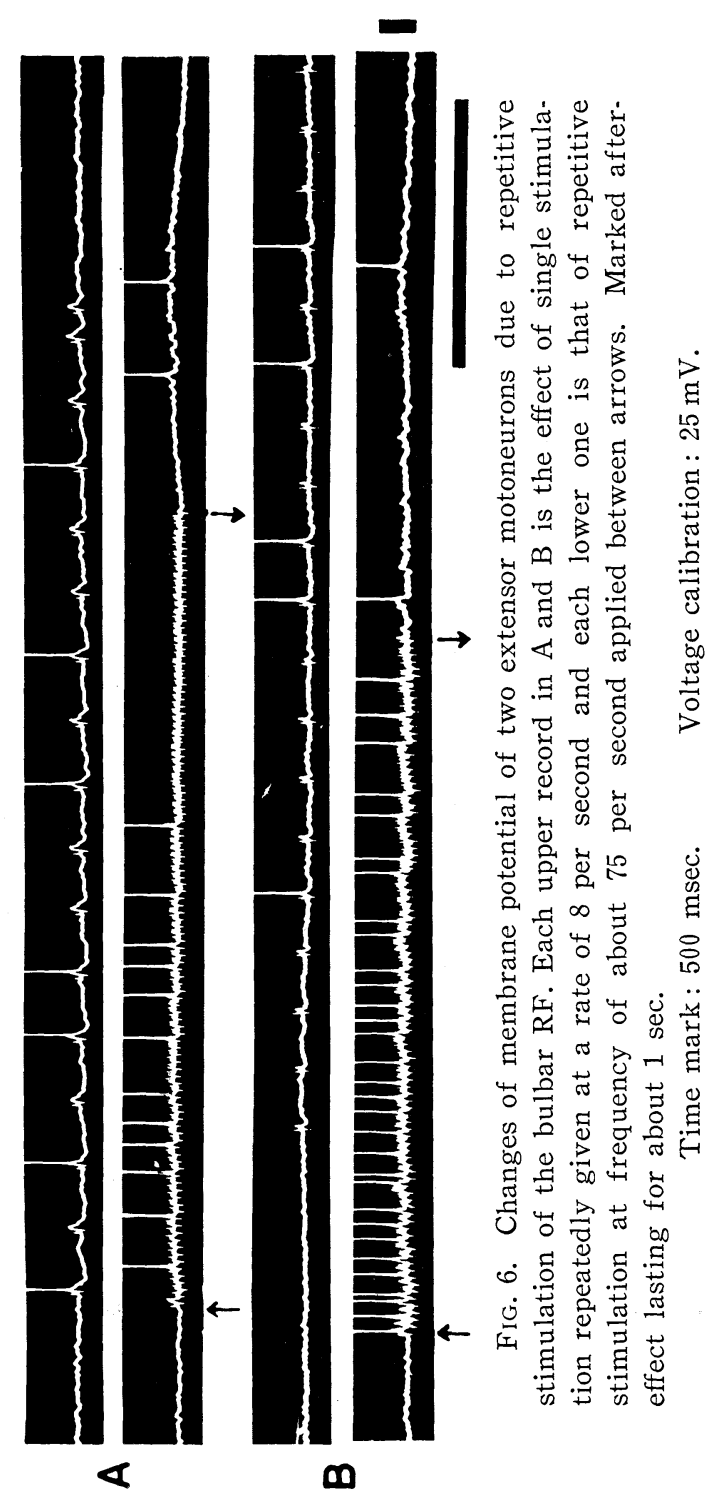

tion which lasted for about one second carrying sporadic spike discharges. The delayed development and long duration of this after-effect seemed to suggest that some complex mechanisms in the brain such as reverberation, after-discharge, disinhibition or other, may be involved.

4. Tonic activities of descending tract fibers and spinal interneurons and their protracted response to reticular stimulation.

The microelectrodes inserted into the spinal cord sometimes picked up 
unitary activities of what seemed most likely to be descending tract fibers, most often when the electrode tip was supposedly located ventrolateral to the ventral grey matter. They were activated neither from ventral nor dorsal roots, but excitable from a certain site in the brain stem, permitting surprisingly stable recording. Records presented in FIG. 7, all of which were obtained from the same animal, show temporal correspondence of PSP's in the motoneuron and a train of impulses in descending fibers. Records in the top row are from an extensor motoneuron and those in the middle and bottom rows
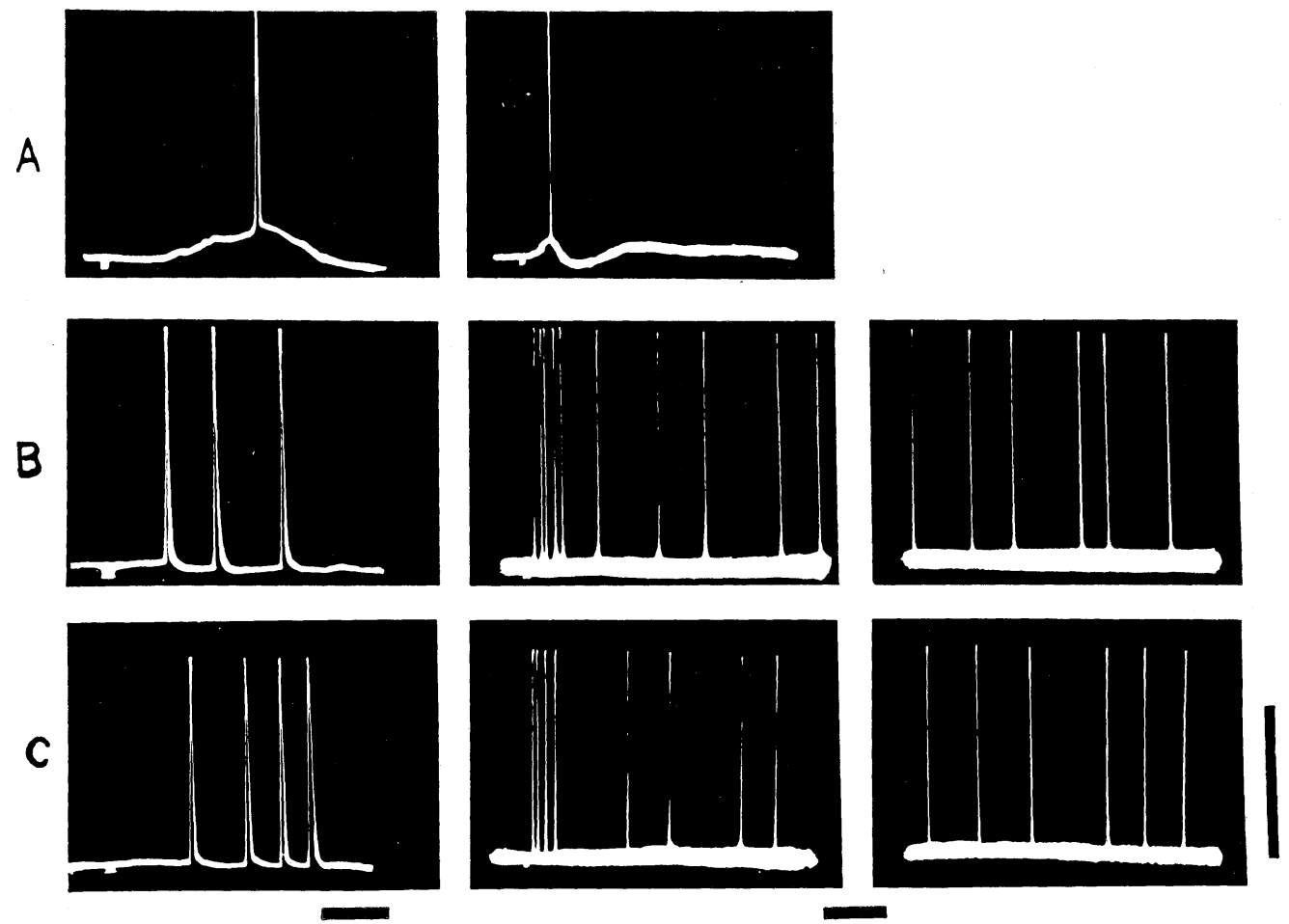

FIG. 7. Tonic impulses in descending tract fibers and their responses to reticular stimulation as compared with motoneuron response.

A : intracellular potentials of a motoneuron upon stimulation of an area in the bulbar RF (faster sweep in the left column).

$\mathrm{B}$ and $\mathrm{C}$ : spike discharges of descending tract fibers elicited by stimuli to the same reticular area as in row A. Two records in the right column show tonic background discharges of respective fibers without electrical stimulus. In the middle column, stimuli applied shortly after the start of sweep evoked several spikes in succession. Records in the left column show the response on expanded time scale.

All were obtained from the same spinal cord. Note temporal coincidence of PSP's in the motoneuron with descending impulses.

Time marks: $10 \mathrm{msec}$. for the left column and $50 \mathrm{msec}$. for the others. Voltage calibration: $50 \mathrm{mV}$. 
are intracellular spikes presumably of descending tract fibers, each row representing one single fiber. These fibers were carrying tonic impulses, as shown in the two right-side records, even without stimulation. Responses of the motoneuron and descending fibers to single stimulation of a certain site in the bulbar RF are presented in the left and middle columns, records to the left being shown in magnified time scale. These and many other similar records prove that the temporal correspondence between the potential changes in the

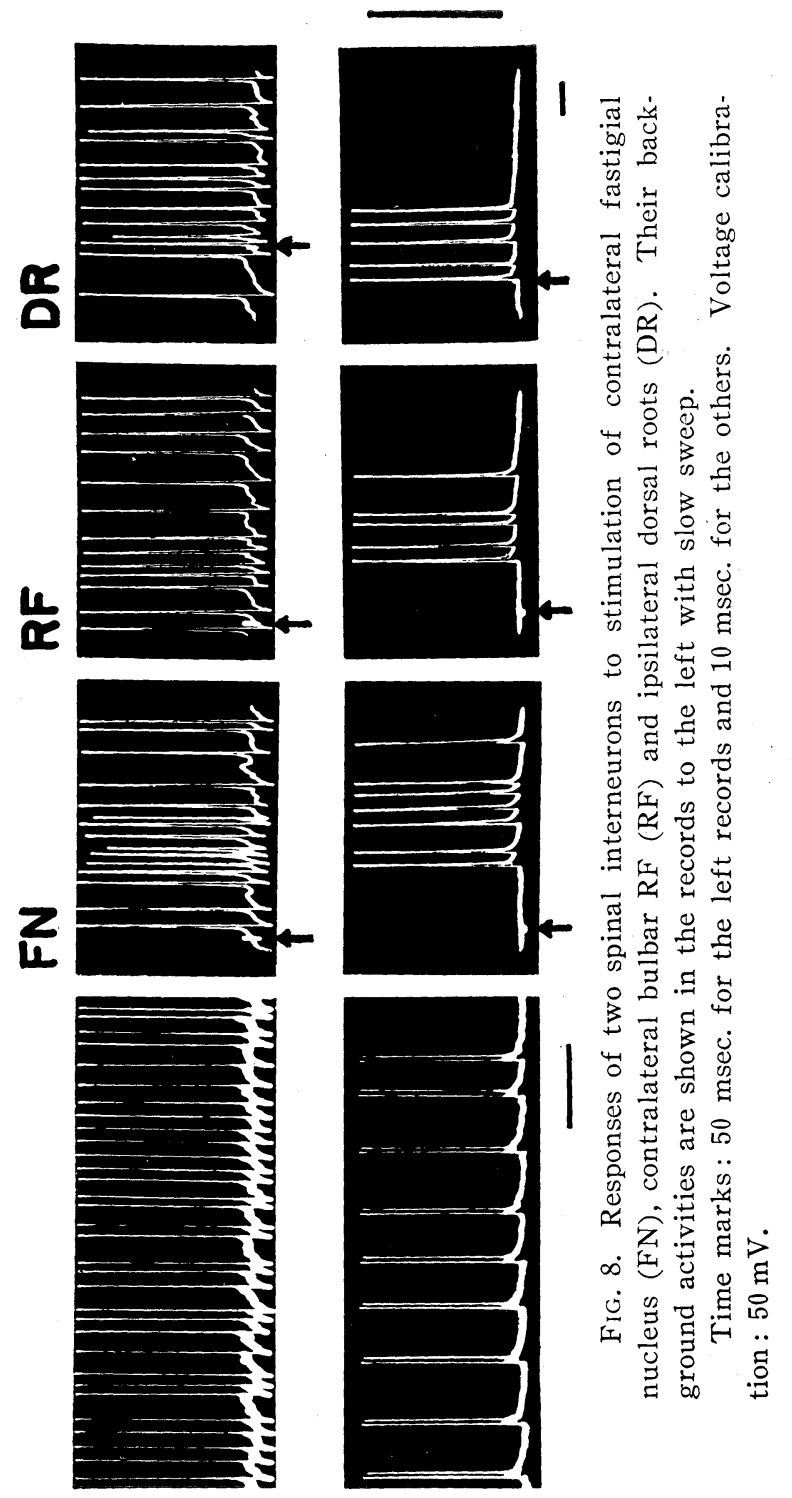


motoneuron membrane and the train of descending impulses is fairly good. In some cases single RF stimulation induced changes in the membrane potential of motoneurons over a period of as long as $100 \mathrm{msec}$. and the descending impulses were recognized dispersed over this whole period. That means, suprasegmental activities, descending directly or indirectly mediated by short propriospinal fibers described by LLOYD ${ }^{8)}$, are almost exclusively responsible for the whole course of events in the motoneuron at least up to $40 \mathrm{msec}$. or so after bulbar stimulation. Activities of spinal interneurons at the final level may necessarily be therein involved, but they may not be of great importance in protracting supraspinal influences.

Maintained discharges of spinal interneurons were also often recorded intracellularly. The interneurons presented in FIG. 8 were activated by stimulation of fastigial nucleus ( $F N$ ) or bulbar $\mathrm{RF}(\mathrm{RF})$ at latencies of $15-20 \mathrm{msec}$. and also by that of dorsal roots (DR) at a short latency and seemed to provide a common path to motoneurons. The effects of these stimulations appeared simply to add several impulses to the background activities.

\section{DISCUSSION}

In conformity with the findings in our previous reports ${ }^{15)}$, facilitatory and inhibitory influences from pontine and bulbar RF on the monosynaptic reflex seem to be interpretable in terms of the potential changes of motoneuron membrane which are most likely to be EPSP's and IPSP's elicited directly or indirectly by descending impulses. Potential changes in the motoneuron membrane were sometimes considerably different from cell to cell even with the same electrode position in the brain stem, although a certain scheme applicable to all varieties was recognized corresponding to each stimulated site. Therefore, with a limited number, however large it might be, of motoneurons intracellularly explored, the above assertion holds only in the qualitative sense and does not preclude the possibility of other mechanisms of reticular influences, whether known or yet unknown ones. Only it can be said that there was no positive support for the mechanism other than that of PSP's.

KoIzUmi, Ushiy Ama and BROOKS ${ }^{\text {7) }}$ have found that single pulse stimulation of the midbrain RF brought about descending discharges lasting for many milliseconds, while it produced a prolonged interneuron activity lasting for as long as $500 \mathrm{msec}$. They attributed the long-lasting effect of RF stimulation upon the spinal reflex mainly to the prolonged response of spinal interneurons. Also SudA, Kolzumi and BROOKS ${ }^{21)}$ observed that the descending discharge following single pulse stimulation of suprabulbar RF persisted for only 20 msec. and could not account for the whole course of facilitatory of inhibitory effects on the spinal reflex which lasted for over $100 \mathrm{msec}$. In the present study, descending impulses following single $\mathrm{RF}$ stimulation lasted usually for about 
40 msec., but on occasion up to $100 \mathrm{msec}$, an interval just long enough in each case of stimulation to cover the whole duration of detected influence upon motoneuron membrane potential or monosynaptic reflex size. The duration of induced interneuron activity was found also within the range of the same order. Therefore, the role of segmental interneurons seems to be of minor importance in protracting supraspinal influences.

In spite of very brief duration of stimuli applied to $\mathrm{RF}$ in the present research, it is of interest to compare the present results with those of previous workers obtained by repetitive stimulation and to discuss them in connection with the normal function of $\mathrm{RF}$ and with decerebrate rigidity. Before entering into detail, however, following points necessitate caution. First, in the present research, indirect influence upon alpha motoneurons through the gamma efferent-muscle spindle loop was excluded by sectioning ventral roots. This will cause considerable difference in the results, since it has been known that reticulospinal influences markedly alter the firing of gamma efferents ${ }^{2,4,5}$. Secondly, the effect of repetitive stimulation is not always easy to predict from the result of single stimulation. Thirdly, influences on the excitability of spinal interneurons were not studied in the present research. Therefore, a part of influences on the polysynaptic reflexes might have been overlooked, without giving rise to any potential changes of the motoneuron membrane.

The above-mentioned reticulospinal influences exerted on the monosynaptic reflex can be summarized as follows. From the midbrain and pontine RF reciprocal effects, i.e., inhibitory to extensor and facilitatory to flexor motoneurons, were obtained on the stimulated side. Almost the same influences were found also on the contralateral motoneurons, except that reciprocality to some extent was noticed between homonymous motoneurons of opposite sides from the rostrolateral part of pontine RF. Influences elicitable from the bulbar RF were so manifold that no single statement would suffice to describe them. In the sense that the results similar to those of pontine stimulation were not infrequently encountered from scattered regions of the bulbar RF, the bulboreticular influence was also partly reciprocal. Predominant effects, however, were the types characterized by facilitation, as shown in FIG. $2 \mathrm{E}$ and F. These types were considered to be proper to bulbar RF, because they never came to appear with stimulation of upper regions of the brain stem, and especially because the prevalence of these types over the inhibitory type was most pronounced when the animal was seemingly most wakeful. The effects upon extensor and flexor motoneurons were not identical and revealed something of reciprocality, although the inhibitory effect was generally slight.

With repetitive stimulation of bulbar RF, GERNANDT and THULIN ${ }^{3)}$ could find small, well-circumscribed regions where stimulation produced definite reciprocal effects on the reflex discharges with antagonistic functions. They found that these regions lay within the inhibitory or facilitatory regions first 
asserted by MAGOUN and co-workers, which exhibited non-discriminative, generalized effects on all kinds of motor performances. The reciprocal effect, which they found easier to obtain from medial RF than from lateral RF, was inhibitory to extensor and facilitatory to flexor neurons. Turning to the present results, a reciprocal effect similar to that of GERNANDT and THULIN would be expected, if the slight inhibitory effect following facilitation of extensor motoneurons in FIG. 2E should become predominant over preceding facilitation in the case of repetitive stimulation. This assumption seems, however, rather improbable, because continued depolarization and spike discharges, with more or less rapid adaptation, resulted in extensor motoneurons from repetitive stimulation of bulbar RF, where single stimuli produced depolarization followed by hyperpolarization of the same motoneuron membrane (FIG. 6).

A result characteristic of stimulation of the lateral part of bulbar RF was facilitatory to extensor monosynaptic reflex which came to appear in two phases. The late facilitatory effect was very much like that recognized by stimulating Deiters' nucleus.

It would be quite an adventure to infer from the result of single stimulations to the cause of decerebrate rigidity (cf. 10,11, 12, 14, 17, 18). However, it seems to us that the results in the present and preceding papers ${ }^{15}$ ) provide an attractive preparatory explanation for that phenomenon. Namely, transection of the brain stem at the mid-collicular level will release the extensor tone from inhibitory influences exerted by the red nucleus and midbrain RF. It has been already demonstrated by INGRAM and RANSON ${ }^{6)}$ that the isolated destruction of the red nucleus, or section of its descending projection, did not bring about the rigidity if the remaining brain portion was intact. But exclusion of the red nucleus and midbrain RF, when effected with simultaneous elimination of inhibitory projections from the cerebral cortex and caudate nucleus, might produce the rigidity. The present investigation shows that the most powerful inhibition upon extensor monosynaptic reflex comes from rostral part of pontine RF. This seems to account for our common experience that the decerebrate rigidity is emphasized when the transection has been made more caudally to injure this inhibitory region directly or indirectly through circulatory insufficiency. The muscular tone would then be managed mainly by facilitatory streams from bulbar RF and Deiters' nucleus, controlled only by cerebellar centers ${ }^{1,19)}$.

Histological investigation showed that the effective sites of stimulation in pontine and bulbar RF distributed mainly in RPO, RPC and Rgc areas in FIG. 1. These areas coincide with the regions from which the reticulospinal tracts may originate as revealed by retrograde degeneration following the section of the cervical cord in kittens (TORVIK and BRODAL) ${ }^{22}$.

A brief comment should be added here concerning variable firing level of the motoneuron membrane potential (FIG. 4). This will no doubt most ade- 
quately be interpreted in terms of accommodation of the spinal motoneurons. A systematic study has already been made concerning accommodation of cat's motoneurons and reported elsewhere ${ }^{16)}$.

\section{SUMMARY}

1. Pontine and bulbar reticular formation (RF) and Deiters' nucleus were stimulated stereotaxically with brief electric stimuli (2-3 msec.) and their effects. on the intracellular potential of lumbar alpha motoneurons as wall as on the size of monosynaptic reflex were studied in the cat. Secondary effects through the gamma efferents-muscle spindle loop were eliminated.

2. Stimulation of pontine RF, especially its rostral part, produced a marked inhibition of extensor monosynaptic reflex at a latency of $15-20 \mathrm{msec}$. and a slight facilitation of flexor monosynaptic reflex at a latency of about $10 \mathrm{msec}$.

3. Stimulation of Deiters' nucleus was facilitatory to extensor monosynaptic reflex. The facilitation appeared in two separate phases, the one set up at a latency of less than $10 \mathrm{msec}$. with relatively short and simple time course and the other at a latency of $15-20$ msec. with a longer duration.

4. The effect of stimulation of the bulbar $R F$ varied extensively with a slight change in the electrode position. The most prevalent effect was facilitatory to extensor monosynaptic reflex, which in some cases resembled that of Deiters' nucleus in its time course.

5. Generally speaking, changes by stimulation of intracellular potential of spinal motoneurons reflected the influences elicitable from the same site upon the size of monosynaptic reflex. Facilitatory or inhibitory influence upon the reflex size could mostly be accounted for by the potential change of the motoneuron membrane which was most likely due to EPSP's and IPSP's.

6. Single spinal motoneurons fired from different levels of depolarization, when the rate of rise of depolarizing PSP's was different according to the stimulated site in the brain stem.

7. The effect of repetitive stimulation of the RF on the membrane potential of single spinal motoneurons could be illustrated in general as a summated effect of single stimulation of the same site.

8. Tonic suprasegmental influences and their modification by reticular stimulation were visualized as maintained discharges of descending tract fibers and spinal interneurons.

9. A hypothetical account for the decerebrate rigidity was put forward based on the present findings.

We are indebted to Prof. T. OTANi for advice and criticism. 


\section{REFERENCES}

1) Baumgarten, R., von, Mollica, A. und Moruzzi, G. Modulierung der Entladungsfrequenz einzelner Zellen der Substantia reticularis durch corticofugale und cerebelläre Impulse. Pflügers Arch. 259: 56-78, 1954.

2) Eldred, E., Granit, R. and Merton, P. A. Supraspinal control of the muscle spindles and its significance. J. Physiol. 122: 498-523, 1953.

3) Gernandt, B. And Thulin, C. A. Reciprocal effects upon spinal motoneuron from stimulation of bulbar reticular formation. J. Neurophysiol. 18: 113-129, 1955.

4) Granit, R., Holmgren, B. And Merton, P.A. The two routes for excitation of muscle and their subservience to the cerebellum. J. Physiol. 130:213-224, 1955.

5) Granit, R. And KAADA, B. R. Influences of the stimulation of central nervous structures on muscle spindle in cat. Acta Physiol. Scand. 27:130-160, 1952.

6) Ingram, W. R. And Ranson, S.W. Effects of lesions in the red nuclei in cats. Arch. Neurol. Psychiat., Chicago, 28 : 483-512, 1932.

7) Kolzumi, K., Ushiyama, J. ANd Brooks, C. McC. A study of reticular formation action on spinal interneurons and motoneurons. Jap. J. Physiol. 9: 282-303, 1959.

8) LLOYD, D. P.C. Activity in neurons of the bulbospinal correlation system. $J$. Neurophysiol. 4 : 115-134, 1941.

9) Magoun, H. W. And Rhines, Ruth. Inhibitory mechanism in bulbar reticular formation. J. Neurophysiol. 9 : 165-171, 1946.

10) Magnus, R. Welch Teile des Zentralnervensystems müssen für das Zustandekommen der tonischen Hals- und Labyrinthreflexe auf die Körpermuskulatur vorhanden sein? Pflügers Arch. 159: 223-250, 1914.

11) Pollick, L. J. And Davis, L. Studies in decerebration. VI. The effect of deafferentation upon decerebrate rigidity. Amer. J. Physiol. 98: 47-49, 1931.

12) Rademaker, G. G. J. Die Bedeutung der roten Kerne und des übrigen Mittelhirns für Muskeltonus, Körperstellung und Labyrinthreflexe. Berlin, Julius Springer. 1926. (Cited from Fulton, Physiology of the nervous system, Oxford University Press. 1951).

13) Rhines, Ruth and Magoun, H. W. Brain stem facilitation of cortical response. J. Neurophysiol. 9 : 219-229, 1946.

14) Rossi, G.F. And Zanchfiti, A. The brain stem reticular formation. Arch Ital. de Biol. 95: 199-435, 1957.

15) Sasaki, K., Namikawa, A. and Hashiramoto, S. The effect of midbrain stimulation upon alpha motoneurons in lumbar spinal cord of the cat. Jap. J. Physiol. $10: 303-316,1960$.

16) Sasaki, K. And OtAni, T. Accommodation in spinal motoneurons of the cat. Jap. J. Physiol. 17: 443-456, 1961.

17) Schreiner, L. H., Lindsley, D. B. and Magoun, H. W. Role of brain stem facilitatory systems in maintenance of spasticity. J. Neurophysiol. 12: 207-216, 1949.

18) Sherrington, C.S. Decerebrate rigidity, and reflex coordination of movements. J. Physiol. 22 : 319-332, 1898.

19) Snider, R.S., McCulloch, W.S. and Magoun, H. W. A cerebellobulbo-reticular pathway for suppression. J. Neurophysiol. 12: 325-334, 1949.

20) Sprague, J. M. and Chambers, W. W. Control of posture by reticular formation and cerebellum in the intact, anesthetized and unanesthetized and in the decerebrate cat. Amer. J. Physiol. 176: 52-64, 1953.

21) Suda, I., Kolzumi, K. And Brooks, C. McC. Reticular formation influences on neurons of spinal reflex pathway. J. Neurophysiol. 21 : 113-123, 1958.

22) Torvik, A. And Brodal, A. The origin of reticulospinal fibers in the cat. An experimental study. Anat. Rec. $128: 113-135,1957$. 